\title{
JOHN L. AUSTIN: EL PAPEL DE LA RETÓRICA EN LA PERIFERIA DE LA FILOSOFÍA
}

\author{
MARÍA ISABEL RODRÍGUEZ PONCE \\ Universidad de Extremadura
}

\begin{abstract}
RESUMEN: Este artículo analiza una variedad de aspectos (biográficos, históricos, teóricos, metodológicos) que aportan luz sobre la peculiaridad de John L. Austin y su filosofía, así como sobre el rechazo que se generó hacia ella. De entre todas estas facetas, este trabajo destaca las estilísticas y discursivas, especialmente el papel de la retórica, con el fin de mostrar cómo este autor crea una prosa performativa en perfecta consonancia con su contenido intelectual. De este modo, Austin dota a su obra de una excepcional coherencia entre contenido y forma.
\end{abstract}

PALABRAS CLAVE: John L. Austin; Filosofía del lenguaje ordinario; Discurso filosófico; Análisis del discurso; Retórica.

\section{John L. Austin: the role of rhetoric in the periphery of philosophy}

ABSTRACT: This paper analyses a variety of issues (biography, history, theory, methodology...) that throw light on the peculiarity of John L. Austin and his philosophy, as well as on the rejection generated against it. From all these aspects, this study intends to highlight the stylistic and discursive ones, especially the role of rhetoric, whit the aim to show that this author creates a performative prose in line with its intellectual content. In this way, Austin gives to his work a unique coherence between content and form. KEY WORDS: John L. Austin; Philosophy of Ordinary Language; Philosophic Discourse; Discourse Analysis; Rhetoric.

\section{INTRODUCCIÓN}

En la valoración de la figura y de la obra de John L. Austin por parte de la mayoría de los estudiosos hay un rasgo que se repite de manera casi unánime: la originalidad, el carácter de choque con su entorno. Sus críticos se quejan de que en sus escritos no se identifica ningún problema filosófico estándar ${ }^{1}$, y no acaban de entender qué pretende hacer exactamente ${ }^{2}$. Sus nuevos enfoques sobre conceptos como conocimiento y verdad dejaron desconcertados a muchos profesionales y no profesionales de la filosofía ${ }^{3}$, y, de hecho, la propia investigación científica, de la época y actual, recoge abundantes testimonios y menciones del repudio y de las

1 Warnock, G. J., «John Langshaw Austin: a Biographical Sketch», en: Fann, K. T. (ed.), Symposium on J. L. Austin, London, Routledge and Kegan, 1969, pp. 3-21 (p. 15).

2 Gustafsson, M., «Introduction: Inheriting Austin», en: Gustafsson, M. y Sørli, R. (eds.), The Philosophy of J. L. Austin, N. York, Oxford University Press, 2011, pp. 1-31 (p. 15).

3 Nusserber, S., «Avner Baz, When Words Are Called For: A Defense of Ordinary Language Philosophy, Harvard University Press, 2012, 238pp.» en Notre Dame Philosophical Review, 07/06/2012, p. 3. Disponible en http://ndpr.nd.edu/news/31247-when-words-are-called-for-adefense-of-ordinary-language-philosophy/. 
malas interpretaciones del trabajo de Austin ${ }^{4}$. Esta situación termina derivando incluso hacia la caricatura ${ }^{5}$.

Con Austin se ha incurrido en la simplificación excesiva, precisamente una de las tendencias que él mismo más criticaba en filosofía. En distintas ocasiones, Warnock ${ }^{6}$ ha manifestado que mucho de lo dicho sobre Austin está viciado por una falta de comprensión no ya de sus trabajos, sino de su propia persona y de sus intenciones. Por ejemplo, la idea austiniana de que los filósofos deben estudiar detalladamente el lenguaje ha sido "fantastically misinterpreted ${ }^{7}$ ». Esto puede resumirse, según Warnock $^{8}$, en dos asunciones totalmente erróneas: 1) que los problemas filosóficos están generados completamente por confusión o mal uso del lenguaje y 2) que el lenguaje ordinario es sacrosanto, inmune al criticismo y no susceptible de ampliación y enmienda. El propio Austin reconoció que el lenguaje ordinario puede llegar a ser confuso, incoherente y totalmente inadecuado para ciertos fines. Pero estos matices se han obviado en general, y se ha procedido a duras acometidas contra su metodología de análisis lingüístico ${ }^{9}$ e incluso a defenestrar de una manera un tanto irreflexiva y poco «caritativa ${ }^{10}{ }$ la validez metodológica y teórica de su propuesta.

El resultado de todo esto es una imagen obsoleta y momificada ${ }^{11}$, tanto del filósofo como del tipo de filosofía que intentó instaurar. El giro lingüístico, que irrumpió como una fulgurante estrella en el ámbito filosófico de los años 40 y 50 del siglo $\mathrm{XX}$, se enfrió repentinamente en los 60 y 70, incluyendo el derrocamiento póstumo de Austin ${ }^{12}$. En este proceso de momificación, además de los ataques recibidos en aquella época por parte de Gellner, Russell, Ayer, Bergman, Rorty y otros, lo que más ha influido es que la transmisión de las ideas de Austin se ha realizado de manera indirecta, principalmente a través de Searle y Grice, que han constituido la fuente primera sobre la teoría de los actos de habla para otros filósofos ${ }^{13} \mathrm{y}$, por supuesto, para toda la corriente lingüístico-pragmática posterior.

Otra vía de transmisión de las ideas de Austin mediante una descarnada crítica en los años 70 fue la que abrió Derrida ${ }^{14}$, en la que Austin tuvo como paladín a

4 Quine, W. V., «Jonh L. Austin: Comment» en: Journal of Philosophy, 62-19, 1965, pp. 209-510; Hampshire, S., «John L. Austin and Philosophy» en: Journal of Philosophy, 62-19, 1965, pp. 511-513; CAVell, S., "Austin at Criticism» en: Philosophical Review, 74, 1965, pp. 204-219; RoRTy, R., El giro lingüístico. Dificultades metafilosóficas de la filosofía lingüística, Barcelona, Paidós, 1990 [1967] (traducción de Gabriel Bello); SBISÀ, M., «How to read Austin» en: Pragmatics, 17, 2007, pp. 461-473; Nusseibeh, S., o. c.

5 Gustafsson, M., o. c. p. 2.

6 Warnock, G. J., «Foreword», en: Berlin, I. (ed.), Essays on J. L. Austin, Oxford, Clarendon Press, 1973, p. v.

7 WARNOCK, G. J., o. c. 1969, p. 12.

$8 \quad$ Ibid.p. 17.

9 RoRTY, R., o. c. pp. 163-164

10 Gustafsson, M., o. c. p. 8.

$11 \quad$ Ibid. pp. 2-3.

$12 \quad$ Ibid. p. 3.

13 Ibid. pp. 16-17; Zwagerman, S., Wit's End. Women's Humor as Rhetorical and Performative Strategy, Pittsburgh, University of Pittsburgh Press, 2010, p. 19.

14 Derrida, J., «Firma, acontecimiento, contexto», en: Derrida, J., Márgenes de la filosofía, Madrid, Cátedra, 1998 [1971], pp. 347-372 (traducción de C. González Marín). 
Searle. A partir de entonces se creó una noción de performatividad que ha influido enormemente en estudios literarios, históricos, culturales y artísticos ${ }^{15}$. Pero al igual que sucedió en el ámbito filosófico, la mayoría de estos estudios no acceden de forma directa a las ideas de Austin, sino que lo hacen en segunda o tercera instancia a través de Derrida o de Butler ${ }^{16}$, salvo honrosas excepciones (como la propia Butler, Felman o Zwagerman). En definitiva, dejando a un lado la desafortunada circunstancia de la desaparición prematura de Austin, resultan muy llamativas, por un lado, la insistencia más o menos inconsciente que se ha puesto durante tantos años en oscurecer una figura tan brillante, con una herencia tan larga y profunda, más aún incluso fuera de la filosofía; y, por otro, la tendencia a filtrar o maquillar el discurso original de alguien cuya vía de comunicación plena había sido el trato directo y personal, tal y como testimonian sus colegas o discípulos ${ }^{17}$. Esto solo puede comprenderse bien analizando tanto los factores de rechazo que atañen a la propia figura de Austin, en los que nos detendremos más adelante, como los que se refieren a la polémica etiqueta filosofía lingüística, sobre los que profundizaremos a continuación.

\section{El RECHAZO HACIA LA FILOSOFÍA LINGÜÍSTICA}

El rótulo filosofía lingüística ha causado generalmente prevención e incluso desaprobación, juntamente con su contenido. Rorty, en la época en la que todavía la veía con buenos ojos, llega a decir que la filosofía lingüística había conseguido en los últimos treinta años poner a la defensiva a la tradición filosófica entera, de Parménides a Descartes y Hume hasta Bradley y Whitehead ${ }^{18}$. A veces se toma como sinónimo de filosofía del lenguaje ordinario, y aunque esta última no era monopolio de Austin ni de Oxford, sí que se la asocia con un grupo de filósofos de esta universidad, a los que pueden añadirse más tarde Moore, Russell y Wittgenstein, de Cambridge; quizás por ello filosofía lingüística también se emplea a veces como sinónimo de filosofía analítica ${ }^{19}$. Asimismo, se la vincula con una determinada

15 BaL, M., Travelling concepts in the Humanities, Toronto, University of Toronto Press, 2002; Butler, J. (ed.), Excitable speech: A politics of the performative, N. York, Routledge, 1997; Felman, S., The Literary Speech Act. Don Juan with J. L. Austin, or Seduction in two Languages, Ithaca, Cornell University Press, 1983; PARKer, A. y SEDGwick, E. K., Performativity and Performance, London, Routledge, 1995; Zwagerman, S., o. c.

16 Gustafsson, M., o. c. p. 16.

17 Ibid. p. 4. Lo mismo puede decirse de la difusión de las ideas de Austin mediante la traducción de su obra. Precisamente este trabajo es un primer paso hacia el análisis de la traducción de How to do things with words al español. Para hacerlo con un mínimo de rigor científico es imprescindible realizar todos estos planteamientos sobre la persona del autor, su obra, entorno y encuadre filosófico. La culminación de este estudio es una nueva propuesta de traducción al español de Austin, J. L., How to do things with words: The Williams James Lectures delivered at Harvard University in 1955, Oxford, Oxford University Press, 1975. Se trata de la segunda edición de J. O. Ursom y Marina Sbisà. En adelante se empleará la sigla $H T W$ para referirse a ella en este trabajo.

18 RoRTY, R., o. c. pp. 115-116.

19 Korta, K., «Hacer filosofía del lenguaje» en: Revista de Filosofía, 27-2, 2002, pp. 337359 (p. 343). 
metodología que enfoca los problemas filosóficos a través del análisis del uso de las palabras (no solo de su significado), dando por hecho que el lenguaje ordinario es una herramienta pulida a través de milenios y que contiene distinciones muy sutiles y perfectamente válidas para el desarrollo y la expresión de la ciencia y de la filosofía.

Este era uno de los puntos débiles de la filosofía del lenguaje ordinario para otros filósofos considerados también dentro de la filosofía analítica, pero desde una perspectiva más formalista, como Russell, que llegó a calificarla de «filosofía sin lágrimas ${ }^{20} »$, sustituta del trabajo filosófico verdaderamente honrado ${ }^{21}$, ya que no se aclaraba de forma precisa cómo podían elucidarse los conceptos mediante este método ${ }^{22}$, se detectaba en ella falta de delimitación entre significado y uso ${ }^{23}$, empleaba la intuición como herramienta de investigación filosófica y presentaba un alto grado de empirismo ${ }^{24}$; es decir, no existía una teoría como tal según los cánones tradicionales.

Por otra parte, en la defensa de las bondades del lenguaje ordinario subyacía lo que podía entenderse como una grave acusación a la forma de actuar de la filosofía anterior en general y de los filósofos coetáneos en particular: los problemas filosóficos tradicionales son tales por una mala formulación, por un mal uso del lenguaje. Son "pseudoproblemas». Bien formulados, se resolverían o, mejor dicho, se disolverían ${ }^{25}$, afirmación prototípica del carácter revolucionario y radical de Austin $^{26}$. Entendida sin matices, la idea suscita una gran polémica sobre el sentido y la utilidad del trabajo filosófico en sí mismo (en cierto modo, podría decirse que lo clausura) y al mismo tiempo puede ofrecer una imagen tremendamente pretenciosa y arrogante de quien la enuncia, como fue el caso $^{27}$.

Podrían añadirse muchos más datos que, ante algunos ojos, hacen aparecer a la llamada filosofía lingüística como algo cercano a una aberración psico- o sociológica, en palabras de Gellner ${ }^{28}$, o como un anacronismo vergonzante ${ }^{29}$, aunque

20 Rodríguez-Consuegra, F., «La filosofía del lenguaje: su naturaleza y su contexto» en: Diánoia, 48-50, 2003, pp. 41-68 (p. 64).

21 RoRTy, R., o. c. p. 50.

22 Korta, K., o. c. p. 343.

23 Nusseibeh, S., o. $c$.

24 Rorty, R., o. c. p. 64.

25 Ibid. p. 71.

26 Felman, S., o. c. pp. 61-62; Miller, J. H., Speech Acts in Literature, Stanford, Stanford University Press, 2001, p. 14; BAZ, A., "Knowing Knowing (that Such and Such)», en: Gustafsson, M. y Sørli, R., o. c. pp. 146-174; Narboux, J.-P., «There's Many Slip between Cup and Lip': Dimension and Negation in Austin», en: Gustafsson, M. y Sørli, R., o. c. pp. 204-240.

${ }_{27}$ En esta misma línea, R. RoRTy (o. c. pp. 52-53) menciona como otra posible causa del rechazo la continuidad que la filosofía lingüística se atribuyó con respecto a la gran tradición filosófica, a los antiguos filósofos griegos.

28 La crítica de GeLLnER a la filosofía del lenguaje ordinario, eminentemente en Words and Things (1959), fue bastante agresiva y carente de fundamento, como demuestra UscHANOv, T. P., «Ernest Gellner criticism of Wittgenstein and ordinary language philosophy», en: Kitching, G. y Pleasants, N. (eds.), Marx and Wittgenstein: Knowledge, Morality and Politics, London, Routledge, 2002, pp. 23-46.

29 RoRTY, R. o. c. pp. 52 y 160. 
todo lo expuesto es más que suficiente para confirmar que a la filosofía del lenguaje ordinario se le dio de lado, se la silenció, sobre todo después de la prematura muerte de Austin y hasta nuestros días, en que empieza a haber signos de reivindicación de su figura y de sus ideas ${ }^{30}$. En cualquier caso, quizás el argumento de más peso para explicar esta anulación en cuanto a un filósofo en particular se encuentre en un rechazo de nivel superior, en lo que se refiere al concepto de filosofía del lenguaje en general.

Para empezar, no hay acuerdo sobre qué papel debe ocupar la filosofía del lenguaje con respecto al resto de dominios de la filosofía ${ }^{31}$. Autores como Auroux y Kouloughli o Harris ${ }^{32}$ recuperan la pregunta de Katz y Fodor en 1962, «What's wrong with the philosophy of language?», precisamente para desacreditar este concepto. Harris $^{33}$ afirma que la filosofía del lenguaje no ofrece ninguna explicación sobre el conocimiento lingüístico, simplemente lo da por sentado. Auroux y Kouloughli ${ }^{34}$ sostienen que desde los años 60 no ha habido producciones teóricas importantes en filosofía del lenguaje porque los filósofos actuales no están interesados en abordar la gran cantidad de conocimientos empíricos y técnicos existentes sobre la estructura del lenguaje y se contentan con buscar principios abstractos sobre el mismo.

A diferencia de lo que sucedía en la filosofía tradicional, el acceso filosófico a la naturaleza del objeto ha dejado de ser directo y se efectúa a través de la ciencia empírica correspondiente ${ }^{35}$ : hay una filosofía de las matemáticas, de la física, etc. Cada una de estas filosofías se centra en los fundamentos epistemológicos y metodológicos de esas disciplinas, no en sus verdades empíricas. Del mismo modo, debería haber una filosofía de la lingüística, pero no del lenguaje. Este es el punto clave de la polémica, ya que algunos admiten que sí hay un acceso directo al objeto de estudio (el lenguaje), y que la mediación de la lingüística no es necesaria ${ }^{36}$.

Si la visión de una filosofía de la lingüística, pero no del lenguaje, no está aún perfectamente clara se debe principalmente a los problemas en la consideración de la lingüística como ciencia, así como a su heterogeneidad temática y metodológica ${ }^{37}$. Korta añade a estos la falta de entendimiento entre filosofía del lenguaje y lingüística en el siglo $\mathrm{XX}^{38}$. Ambas disciplinas han seguido, de forma consciente e intencionada,

30 Gustaffson, M. y Sørli, R., o. c.; Baz, A., When Words Are Called For: A Defense of Ordinary Language Philosophy, Harvard University Press, 2012.

31 Korta, K., o. c. p. 343.

32 Auroux, S. y Kouloughti, D., "Why is there no "true" philosophy of linguistics?», en: Harré R. y Harris, R. (eds.), Linguistics and philosophy: the controversial interface, Oxford, Pergamon Press, pp. 21-44; HARRIS, R., «What is philosophy of linguistics?», en: Harré, R. y Harris, R. (eds.), o. c. pp. 3-20.

33 HARRIS, R., o. c. p. 4.

34 Auroux, S. y Kouloughli, D., o. c. p. 27.

35 KORTA, K., o. c. p. 344.

$36 \quad I b i d$. A este respecto, Austin tenía ideas muy claras y avanzadas. Como testimonia Warnock (o. c. 1969, pp. 11-12), Austin pensaba que la filosofía era un residuo enmarañado de una maraña aún mayor. Al ir tomando el conocimiento forma de disciplinas independientes (matemáticas, física, lógica, psicología...) lo que queda bajo el rótulo de filosofía es demasiado heterogéneo como para constituirse en ningún tipo de problema.

37 Auroux, S. y Kouloughli, D., o. c. p. 31.

38 KorTa, K., o. c. pp. 347-348. 
caminos muy distintos, y por ello muchos opinan que la filosofía del lenguaje no ha cumplido el papel de filosofía de la lingüística. Pero, en palabras de Korta, se puede dar la vuelta al argumento: ha sido precisamente la filosofía del lenguaje (más en concreto la filosofía del lenguaje ordinario) la que ha fundamentado teóricamente las ramas más importantes de la lingüística reciente: la semántica y la pragmática. $\mathrm{Y}$ aquí Austin adquiere un papel esencial. Si en el ámbito filosófico sus ideas fueron severamente criticadas e incluso valoradas como un fracaso, en el terreno lingüístico abrió una nueva dimensión con un profundo aprovechamiento. Korta afirma que estos filósofos no hicieron lingüística, sino que sentaron las bases para su desarrollo teórico y sistemático posterior ${ }^{39}$. En lo que se refiere a Austin, hay que decir que la muerte le sorprendió trabajando en la discutida y mal definida frontera entre los dos $\operatorname{campos}^{40}$, pero que nunca le preocupó en exceso cómo se etiquetase desde fuera su investigación ${ }^{41}$.

\section{Las PeCUliaridades de Austin}

\subsection{Aspectos personales y formativos}

En primer lugar, los que conocieron personalmente a Austin le describen como un auténtico "prodigio intelectual ${ }^{42}$ » y, lo que es aún más importante, alguien con un «formidable campo magnético ${ }^{43}$ » y con un impresionante despliegue de autoridad natural, de tal forma que en Oxford se convirtió en una especie de «centro de gravedad ${ }^{44}$ ». Al mismo tiempo, tenía un lado tímido, reservado, incluso distante, por lo que a algunos les pudo parecer una personalidad fría ${ }^{45}$; y nunca reconoció un error públicamente ${ }^{46}$, lo que facilitó que pudiera acusársele de superioridad (aunque en privado ejercía una severa autocrítica ${ }^{47}$ ). Por otra parte, es conocido que expresaba abiertamente su desacuerdo con lo que consideraba que estaba mal, y que no mostraba respeto por las opiniones asentadas irreflexivamente ${ }^{48}$. Si se une esto a la supuesta arrogancia que representaba su hipótesis fundamental (el mal uso del lenguaje por parte de los filósofos) y a la amenaza de una futurible disolución de los problemas filosóficos, no es de extrañar que muchos de sus colegas le temieran (como afirma Pitcher ${ }^{49}$ ), o que al menos no le tuvieran un especial aprecio.

$39 \quad$ Ibid. p. 353.

40 WaRNOCK, G. J., o. c. 1969, p. 19.

41 Carrió, G. R. y Rabossi, E. A. (traductores), «Introducción», en: Austin, J. L., Cómo hacer cosas con palabras: palabras y acciones, Barcelona, Paidós, 1971, pp. 9-35 (pp. 22-23).

42 WARNOCK, G. J., o. c. 1969, p. 3.

43 Warnock, G. J., «Saturday Mornings», en: Berlin, I., o. c. 1973, pp. 31-45 (p. 33).

44 WARNOCK, G. J., o. c. 1969, p. 21.

$45 \quad$ Ibid. p. 19

46 Pitcher, G., «Austin: a personal memoir», en: Berlin, I. (ed.), o. c. 1973, p. 27; WARNOCK,

G. J., «Saturday Mornings», en Berlin, I. (ed.), o. c. p. 35.

47 Pitcher, G., o. c. p. 27.

$48 \quad$ Ibid. p. 28.

49 Ibid. 
Otra particularidad que Austin comparte con más filósofos ingleses pero que al mismo tiempo le singulariza es su formación académica. Austin recibe una formación inicial plenamente lingüística, en lenguas clásicas, y principalmente en griego, en cuyo dominio destaca desde muy joven mostrando una gran destreza para la traducción. Warnock señala que fue en 1931 cuando Austin tuvo su primer contacto serio con la filosofía, pero «he came to that subject already highly accomplished as a classical scholar and linguist ${ }^{50}$ ». Este aspecto es clave en su desarrollo posterior como filósofo, ya que su formación clásica determina su intensa preocupación por la precisión lingüística y su exacerbado interés por el lenguaje. Suele señalarse en él un fuerte influjo aristotélico, no ajeno a las preferencias de Oxford en general. Rorty ${ }^{51}$ subraya la admiración de Austin por Aristóteles y califica de «idiosincráticas» las estrategias de inspiración aristotélica con las que Austin rebate a Russell o a Moore. Pero también hay mucho de platónico y de socrático en Austin $^{52}$, al menos desde el punto de vista metodológico, como se verá más adelante.

\subsection{Aspectos metodológicos}

En cuanto a los aspectos metodológicos, que se imbrican profundamente con la teoría, puede decirse que es donde se halla la vena más radical y revolucionaria de Austin y quizás la parte peor comprendida de su trabajo. Warnock nos informa de que su educación había seguido un patrón muy tradicional, y de que Austin pensaba a veces que había perdido mucho tiempo con ello ${ }^{53}$. Esto le llevó a cuestionar la validez del método educativo tradicional y a plantearse sus propios enfoques al margen de él. De hecho, su perspectiva sobre la enseñanza de la filosofía sufrió un cambio sustantivo tras la Segunda Guerra Mundial, ya que antes había sido mucho más historicista como docente ${ }^{54}$.

\subsubsection{El trabajo colaborativo en filosofía}

Austin trasladó a su quehacer filosófico la experiencia de trabajo en grupo adquirida en sus labores en el servicio de inteligencia británico durante la Segunda Guerra Mundial ${ }^{55}$, en la que su talento brilló especialmente. La idea de la filosofía como trabajo cooperativo, en equipo, es, en realidad, un abordaje muy científico de la investigación filosófica, y lo demuestra claramente el hecho de que está

50 WaRnOCK, G. J., o. c. 1969, p. 4.

51 RoRTy, R., o. c. p. 83.

52 J. H. Miller (o. c. pp. 19 y 59), al reconocer la pertenencia de Austin a la gran tradición filosófica, menciona a Platón y a Sócrates, especialmente a este último, como «augusto predecesor» de Austin en su forma de tratar los problemas, suspendiendo los argumentos para retomarlos más tarde en un nivel todavía más fundamental. J. LeIBER («How J. L. Austin does things with words» en: Philosophy and Literature, 1.1, 1976, pp. 54-65 [p. 65]) lo compara directamente con Sócrates en su estilo docente.

53 Warnock, G. J., o. c. 1969, p. 4.

$54 \quad$ Ibid. p. 5.

55 Nusseibeh, S., o. c. p. 2. 
indisolublemente unida a una de sus premisas teórico-metodológicas. Austin daba importancia, por supuesto, a las cuestiones teóricas y metodológicas generales, pero los que verdaderamente le interesaban eran los problemas particulares, sobre los que se podía establecer un debate más concreto y con ello avanzar en el conocimiento ${ }^{56}$. Esta metodología de trabajo en fragmentos pequeños, aislados, diseccionando minuciosamente el sentido y sin proponer (al menos en primera instancia) teorías generales era también una reacción metodológica contra el estilo de filosofar imperante en Oxford, que había sido una continua batalla de posturas téoricas generales entre bandos enfrentados de filósofos ${ }^{57}$. Sin embargo, en los Saturday Mornings ${ }^{58}$, que se instituyeron tras la guerra, no había antagonismos ni el «gladiatorial style» típico del debate filosófico. Eran reuniones colaborativas, no competitivas, en las que Austin no ponía especial hincapié en que sus colegas o alumnos extrajeran unas determinadas lecciones filosóficas ${ }^{59}$.

\subsubsection{El humor como método}

Aunque más arriba se le ha descrito como reservado y tímido, hay otra faceta de la personalidad de Austin que puede describirse como el núcleo de su metodología filosófica. Son incontables los testimonios que pueden reunirse sobre su lado creativo, divertido y humorístico. Para él existía una peligrosa identificación entre la solemnidad y el fraude ${ }^{60}$, así que, desafiando el riesgo de ser acusado de tomar la filosofía como un mero entretenimiento ${ }^{61}$, en sus clases, conferencias, seminarios...

56 WARNOCK, G. J., o. c. 1969, p. 17.

57 Berlin, I., "Austin and the Early Beginnings of Oxford Philosophy», en: Berlin, I. (ed.), o. c. pp. 1-16 (p. 5).

58 Los Saturday Mornings eran reuniones de dos a tres horas que constituyeron el proyecto piloto para la idea de trabajo colaborativo sistemático de Austin. Tuvieron su precedente antes de la guerra en los Thursday Evenings, como relata I. BERLIN (o. c. pp. 9-10). Un campo de búsqueda (por ejemplo, el concepto de regla) se dividía metódicamente en áreas que se asignaban a los participantes para que investigasen sobre ellas. Procedían así al comienzo, cuando las reuniones eran más formales. Después el grado de formalidad se rebajó. Además de sobre conceptos concretos, también debatían con detalle sobre obras como la Ética nicomaquea de Aristóteles, los Fundamentos de aritmética de Frege, las Investigaciones filosóficas de Wittgenstein, la Fenomenología de la percepción de Merleau-Ponty o las Estructuras sintácticas de Chomsky (Stanford Encyclopedia of Philosophy, disponible en http://plato.stanford.edu). Las reuniones están recogidas por escrito (WARNOcK, G. J., o. c. 1969, p. 14). Austin escribió y publicó muy poco en vida, por lo que este sistema de reflexión filosófica eminentemente oral, a través de clases y seminarios con colegas y alumnos, tiene también un potente valor metodológico de clara inspiración en la accademia platónica, en el núcleo de su formación clásica.

59 Warnock, G. J., «Saturday Mornings», o. c. 1973, p. 35.

60 Warnock, G. J., o. c. 1969 , p. 21.

${ }_{61}$ De hecho, así se expone claramente entre sus comentaristas. R. RoRTy (o. c. p. 93) afirma que la filosofía lingüística, desaprobando el tratamiento habitual de la filosofía como una pseudociencia en la época, se abre a un enfoque de la misma como algo más lúdico, como una nueva forma de arte, y que, en este sentido, el giro lingüístico hizo a la filosofía más consciente de hallarse, desde Platón, en un estado de tensión permanente entre la presión de las artes por un lado y de las ciencias por otro (RORTY, R., o. c. p.127). 
Austin era muy consciente de estar ejecutando una auténtica performance ${ }^{62}$ permeada por el humor y la ironía ${ }^{63}$.

Uno de sus discípulos más cercanos, Pitcher, recuerda cómo en sus reuniones semanales Austin producía un auténtico efecto teatral de suspense por su manera de nunca terminar de encender la pipa con cerillas que iba dejando consumirse ${ }^{64}$. Warnock comenta asimismo: «Quite apart from the fact he enjoyed philosophical argument, Austin liked jokes — sometimes really silly jokes, real farcical fantasy ${ }^{65} \ldots »$. Esto lo testimonian diferentes anécdotas de otros colegas y discípulos allegados a él. Berlin habla de cómo actuó Austin con él en un seminario que impartían conjuntamente, como si fuera una lucha «a muerte» entre los dos; o explica su cinematográfica forma de preguntar a algunos alumnos, apuntándoles con el dedo como si fuera una pistola ${ }^{66}$.

En todo ello los críticos de Austin observan unos elaborados recursos socráticos que sus partidarios se niegan a aceptar; pero no pueden negar que Austin encontraba «a certain degree of malicious pleasure in blowing up carefully constructed philosophical edifices ${ }^{67}$ ». Queda claro que a Austin le gustaba ejercer cómicamente de abogado del diablo (to play Old Harry with), no solo por el puro placer intelectual de la filosofía, sino también por una auténtica necesidad metodológica. En este

${ }_{62}$ Es obligatorio hacer una reflexión sobre el concepto central de la teoría de Austin, performative utterances. Muchos teóricos han reclamado la consideración de la dimensión teatral de este término (Zwagerman, S., o. c. pp. 10-11). Hay dos acepciones fundamentales de perform en las que coinciden los diccionarios fundamentales (Oxford, Cambridge): una relacionada con DO ('to do an action or piece of work') y otra relacionada con ENTERTAIN ('by dancing, singing, acting...'). El Cambridge marca esta última como B1, y de hecho los derivados de perform (performance, performer, performing acts) se crean a partir de la acepción 'entertain'. Por supuesto, performativo no se puede entender como sinónimo de teatral, sino que la relación entre ellos se establece por vía metafórica (Zwagerman, S., ibid.). En $H T W$ aparecen ejemplos de usos metafóricos e imágenes que refuerzan esta interpretación: al hablar precisamente de los enunciados performativos, en la conferencia I (p. 4) los personifica a través de la aparición de cierto léxico (masqueraders, to masquerade, disguise, to ape), incidiendo en cómo han conseguido engañar tanto a gramáticos como a filósofos; en la conferencia II (p. 12) reelabora la misma idea cuando dice que muestran el «gramatical make-up of statements", pero que no pueden ser verdaderos o falsos; cita a Shakespeare, concretamente en La Tempestad, cuando usa con ánimo metafórico el término sea-change (J. H. Miller, o. c. p. 35); y, además, uno de los puntos más espinosos de su teoría (la exclusión de los usos etiolados del lenguaje, usos «no en serio») está ilustrado con el soliloquio de un actor en escena, que es justamente el papel que él abordaba en sus clases y conferencias. Por otra parte, Austin conocía de primera mano este terreno, como recuerda G. J. WARNock (o. c. 1969, p. 4) cuando habla de su etapa de formación: «He played some games and greatly enjoyed acting with The Balliol Players». De hecho, el impacto que ha tenido después en los estudios literarios y culturales la noción de performatividad, especialmente en el teatro, proviene de este matiz teatral en el concepto de performativo (PARKER, A. y SEDGWIK, E. K., o. c. p. 1).

63 Zwagerman, S., o. c. p. 149.

64 Pitcher, G., o. c. pp. 21-22.

65 Warnock, G. J., «Saturday Mornings», o. c. p. 33. De hecho, S. Felman (o. c. p. 95) llega a calificarle como «a jester», («bromista», «bufón»).

66 Berlin, I., o. c. pp. 8-10.

$67 \quad$ Ibid. p. 13. 
sentido, como en muchos otros, Austin es un pensador profundamente sistemático ${ }^{68}$, contra lo que generalmente pudiera creerse.

En cualquier caso, la aparición del humor de una manera estructural en la obra de Austin constituye una de sus aporías más potentes. Desde el punto de vista enunciado en How to do things with words (HTW), el humor, como la literatura, es una etiolación, un uso parásito del lenguaje, y por tanto queda fuera de la teoría de los performativos. Pero en general, y más particularmente en el caso de Austin, esta exclusión del humor no es tan sencilla de ejecutar. En primer lugar, el humor es uno de los fenómenos donde más claramente puede apreciarse el contraste entre lo locutivo y lo ilocutivo, es decir, es una poderosa herramienta performativa, además de retórica. Y, por otra parte, es una herramienta de conocimiento. En Austin el humor no es solo una metodología, sino también una epistemología ${ }^{69}$.

En general, el empleo del humor en la obra de Austin parece haber pasado inadvertido para la mayoría de los investigadores ${ }^{70}$, y algunos de los que sí lo han analizado, como Felman y Miller, le otorgan una apreciación negativa, pues consideran que el humor menoscaba el propio acto de habla que efectúa. Sin embargo, si se comprenden los principios metodológicos de Austin, sucede todo lo contrario: el humor potencia unos postulados que son totalmente en serio ${ }^{71}$. Para darse cuenta de ello no hay más que reflexionar sobre la circunstancia del título How to do things with words, de la que el propio Austin hablaba en sus clases ${ }^{72}$.

Una vez más se da la paradoja de que la obra que desafía los principios fundacionales de la filosofía del lenguaje parodia los títulos de un tipo de libros de autoayuda no académicos (los how-to books) que se habían hecho muy famosos en la época (How to win friends and influence people $e^{73}$ ) y que ya habían sido parodiados por la propia literatura (Mark Twain). En estas how-to parodies literarias no se explica nada en absoluto, por lo que nunca se cumple la promesa del título, en cierto modo como sucede en $H T W^{74}$ : primero se realiza la distinción constativo/ performativo y luego se abandona; después se hace una clasificación de verbos performativos de la que Austin afirma no estar muy satisfecho; y se termina la obra dejando a los lectores «the real fun of applying it in philosophy».

El hecho de unir la filosofía con los manuales de autoayuda paródicos es como casar a una persona con un mono, según reza uno de los famosos ejemplos de Austin $^{75}$ : equivale a poner como piedra angular de su edificio filosófico la metodología del humor incongruente. Al invertir las posiciones del texto filosófico abstracto (abajo) y del how-to book (arriba), cuestiona la superioridad de la filosofía en un ejercicio realmente subversivo que sintetiza teoría y $\operatorname{praxis}^{76}$.

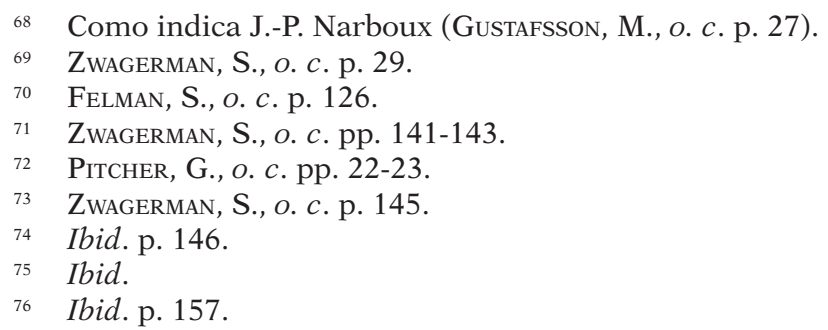




\subsubsection{Los ejemplos}

En el sistema metódico y ordenado de Austin, uno de los aspectos más destacables, en el que encontramos fundidos imaginación, humor, retórica e ironía socrática, son los ejemplos, cuyo carácter llamativo e impactante es reconocido como un marchamo que hace única su filosofía, y cuyo particular uso lo distingue de otros filósofos más tradicionales, como Russell, Broad y Moore, según señala Cavell ${ }^{77}$. En su peculiar manera de entender el procedimiento clásico de la illustratio, Austin maneja materiales de procedencia muy diversa: geográfica, histórica, literaria, de la cultura popular...

Además de esta variedad, los ejemplos suelen estar atravesados, por una parte, por la vena irónica prototípica de esta obra, como cuando se bautiza un barco con el nombre de Mister Stalin o como el caso del cuidador del asilo que escalda a un paciente en el baño y lo mata "por accidente ${ }^{78} »$; y, por otra, por una tendencia al absurdo, a la incongruencia, incluso a lo estrafalario: matrimonios con monos, disparos a burros o bautizos de pingüinos ${ }^{79}$. Miller hace notar que los ejemplos más impactantes de Austin suelen ser misfires, actos infelices: reglas que se rompen, cosas que salen $\mathrm{mal}^{80}$. Como señala Miller, la ley de Murphy se cumple casi inexorablemente en $H T W$, pero todo ello se narra con un tono que oscila súbitamente entre lo serio y lo cómico. La interpretación de este hecho es divergente. Para Felman la elección de estos ejemplos triviales, incongruentes, tiene un efecto analítico, de descentrado en el espacio teórico ${ }^{81}$. Efectivamente, el contraste entre lo serio y lo ridículo, y su efecto cómico indiscutible, responden a un afán de provocación, de cambio, de abandono de los caminos trillados, que es uno de los pilares teóricos y metodológicos de Austin. Hay que hacer hincapié en esta novedad en un entorno filosófico en el que el debate podía girar incansablemente sobre los mismos argumentos y ejemplos. Por eso sus colegas y discípulos afirman que «Austin was absolutely first-hand ${ }^{82}$ ».

Por si lo anterior fuera poco, los ejemplos en la obra de Austin forman parte de una gran paradoja ya mencionada, porque entran en plena contradicción con uno

77 Gusstafsson, M., «Perfect Pitch and Austinian Examples: Cavell, McDowell, Wittgenstein, and the Philosophical Signifiance of Ordinary Language» en: Inquiry, 48-4, 2005, pp. 356-389 (p. 370).

${ }_{78}$ Miller, J. H., o. c. p. 41.

79 Como menciona J. H. Miller (o. c. pp. 15-16), Austin tiene una especial habilidad para crear ejemplos que socavan sus propias hipótesis. En este caso, el bautizo de los pingüinos, tomado de la novela de Anatole France La isla de los pingüinos, parece estar queriendo decir que hay una fuerza ilocutiva estructural en el lenguaje que es independiente de las intenciones que abriguen los sujetos al efectuar un performativo (ZwAGERMAN, S., o. c. p. 151). En ese sentido, Austin estaría dando la razón a las tesis de De Man (Miller, J. H., o. c. p. 174); o a las de Derrida sobre la iterabilidad y el debilitamiento del contexto, que mencionaremos a continuación. J. H. Miller (o. c. p. 172) cree que Austin siempre se queda en la periferia de su teoría, sin llegar nunca al centro, porque está huyendo de esta conclusión; y Baz (GusTAFsson, M., o. c. 2011, p. 25), ponderando el radicalismo y el lado revolucionario de Austin, llega a afirmar que en realidad esta es la conclusión definitiva a la que quería llegar.

80 Miller, J. H., o. c. pp. 49-50.

81 Felman, S., o. c. p. 116.

82 WaRnock, G. J., «Saturday Mornings», o. c. pp. 44-45. 
de sus principios teóricos básicos: la exclusión de la teoría de los performativos de los usos etiolados, "no en serio», que se corresponden fundamentalmente con la literatura, análogamente a cómo Platón expulsó a los poetas de su ciudad ideal. Los ejemplos imaginativos son uno de los tres elementos (junto con la ironía persuasiva y los diálogos ficcionales) por los que Miller atribuye a HTW el estatus de obra literaria ${ }^{83}$. En sí mismos son etiolaciones, usos decolorados del lenguaje, menciones. Nadie pensaría que Austin está tratando realmente de casar a alguien con un mono. Al mismo tiempo, son una de las variadas vías por las que la retórica se introduce en la obra de Austin, ya que se los puede considerar tropos, dentro de la sinécdoque (la parte por el todo ${ }^{84}$ ).

No deja de ser desconcertante que una obra entre cuyos principales planteamientos teóricos está la expulsión de todo lo que contenga una cualidad literaria o retórica esté construida con recursos literarios, con etiolaciones constantes. Esta contradicción sirvió para abrir una de las brechas críticas más vehementes con esta teoría a través del concepto de iterabilidad. Según Derrida ${ }^{85}$, la posibilidad que todos los performativos tienen de ser citados es anormal o parasitaria para Austin, cuando precisamente el éxito o felicidad mayoritaria de los performativos se basa en que dependen de un modelo codificado, iterable, previo. Derrida señala que dentro de la iterabilidad general del discurso, habría iteraciones particulares, como las que se producen en la literatura, el teatro o el humor. De este modo, todo lo que Austin excluyó de su teoría queda automáticamente incluido por su carácter de cita, independientemente de la fuerza ilocutiva de los enunciados.

Pero quizás estas posturas no sean tan irreconciliables como parece y todo provenga de una mala interpretación (una más) de las palabras de Austin. Como sostienen algunos investigadores, cuando Austin separa los usos serios de los no serios no hay por qué interpretar en ello un ánimo estigmatizador e iconoclasta de estos últimos, sino la intención de estudiar lo anormal como constitutivo de lo normal ${ }^{86}$ y también la necesidad metodológica de dividir para poder analizar mejor, como indicaba Searle ${ }^{87}$. En este sentido, Derrida se expresa de manera muy similar cuando habla de las infelicities como una posibilidad estructural, no eventual, de los actos de habla ${ }^{88}$.

Por último, hay otro argumento metodológico esencial que puede aportar algo de luz a esta paradoja. Como indica Felman, ni los partidarios ni los detractores de Austin se detuvieron a analizar la función del humor y la ironía en su obra: solo han prestado atención a lo que decía, no a lo que hacía ${ }^{89}$. Así que, con respecto a las

83 Los ejemplos y los diálogos ficcionales están estrechamente interconectados en la obra de Austin (Miller, J. H., o. c. p. 42), ya que los segundos suelen formar parte de los primeros. Los diálogos son una etiolación más, literaturizan la obra. Es como si provinieran de los personajes de una novela (Miller, J. H., o. c. p. 49). De hecho, J. Leiber (o. c. p. 55) habla de playful personae en la prosa de Austin.

84 Miller, J. H., o. c. p. 43.

85 DERRIDA, J., O. c. pp. 12-14.

86 Felman, S., o. c. p. 139.

87 Zwagerman, S., o. c. p. 131.

88 Derrida, J., o. c. p. 11.

89 Felman, S., o. c. pp. 129-131. 
afirmaciones de Austin sobre el lenguaje usado no en serio, parasitario, literario, Felman se pregunta ¿debemos creer lo que dice? ¿está siendo irónico?, y afirma que en este caso Austin está siguiendo al pie de la letra la paradoja aristotélica sobre la comedia $^{90}$ (De poética, cap. V). Se convierte una vez más en el abogado del diablo, en el eirôn que, con el fin de incitar a la reflexión, siembra la duda sobre la propia doctrina general que está tratando de demostrar, en lugar de presentar verdades teóricas con un carácter definitivo y monolítico.

\subsection{El estilo}

Como ha podido observarse, la especificidad de Austin entre sus coetáneos consiste en una profunda amalgama de fondo y forma, y esto se hace muy patente en cuestiones estilísticas, que en su momento produjeron acercamientos científicos como el de J. Leiber ${ }^{91}$. Solo para hacerse una ligera idea, comparando la frecuencia relativa de varios tipos de estructuras sintácticas en la obra de Austin con la frecuencia de distribución habitual en la prosa filosófica de su época, Leiber observa que Austin emplea más del doble de sentencias exclamativas, interrogativas y modales de lo que era común entonces. Este investigador afirma que para transmitir el concepto de que hablar es una acción, Austin utiliza una «sintaxis de acción ${ }^{92}$ », y se expresa sobre él en los siguientes términos: «He is the punster and dazzling prose stylist ${ }^{93}$ ». Esta afirmación coincide con la opinión de otros muchos estudiosos y traductores, que le consideran un clásico tanto de la filosofía como de las letras inglesas ${ }^{94}$.

El estilo marcado y fuera de lo académicamente común en toda su obra es un hecho que no debe obviarse, sobre todo dado el carácter póstumo de la mayoría de las publicaciones de Austin. En este contexto, HTW destaca especialmente por el esfuerzo de compilación y reconstrucción que supuso y porque, al proceder de unas conferencias, se suele considerar que posee unos rasgos estilísticos peculiares, ligados a la oralidad y a la coloquialidad. El hecho es que toda la obra filosófica de Austin se fraguó de idéntico modo y un tipo de discurso muy similar al de HTW es fácilmente detectable en otras publicaciones del filósofo ${ }^{95}$.

90 La paradoja consiste en que en el drama, tanto en la tragedia como en la comedia, «ambas formas artísticas implican que la vivencia negativa de emociones positivas y su valor estético, al menos en parte, se atribuía a la capacidad de provocar simultáneamente emociones positivas y negativas. En la tragedia se vivencian con placer escenarios de tristeza y agresividad, mientras que en la comedia se alcanza el sentimiento alegre de ridiculez no dolorosa, en términos de Aristóteles», Páez, D. y Adrián, J., Arte, lenguaje y emoción: la función de la experiencia estética desde una perspectiva vigotskyana, Madrid, Fundamentos, 1993, p. 157.

91 LeIBER, J., o. $c$.

$92 \quad$ Ibid.p. 64.

$93 \quad$ Ibid. p. 54.

94 García SuÁrez, A. (traductor), «Presentación», en: Austin, J. L., Ensayos filosóficos, Madrid, Ediciones de la Revista de Occidente, 1975, pp. 11-28 (p. 28).

95 Rajagopalan, K., "Autin's humorous style of philosophical discourse in light of Schrempp's interpretation of Oring's incongruity theory of humor» en: Humor, 13-3, 2000, pp. 287-311 (pp. 300-301). 
En cualquier caso, en su estilo expresivo hay que sopesar cuidadosamente el ámbito oral del que proviene, sobre todo en el caso de $H T W$, elaborado principalmente, entre otros recursos, a partir de las notas de Austin para sus conferencias. Evidentemente, los rasgos orales de una clase o de una conferencia académica no son comparables con los de la oralidad natural del registro coloquial. Normalmente son textos escritos para ser leídos o dichos de memoria, y en ellos conviven, junto a las convenciones propias de la escritura, las marcas características de la oralidad: repeticiones, variaciones en el orden de palabras, determinados marcadores discursivos... Se trata de textos que pertenecen a un modo híbrido ${ }^{96}$ y que podrían acogerse en ciertos aspectos al concepto de oralidad fingida manejado en literatura, teatro y otros medios ${ }^{97}$. Además, en el caso de Austin parece comprobado que ensayaba sus conferencias sin dejar prácticamente nada al azar, incluso en los detalles aparentemente más espontáneos, y las trabajó y pulió durante años ${ }^{98}$.

\section{El papel de la Retórica en la filosofía de Austin}

De todo lo expuesto hasta ahora cabe deducir que el choque o el rechazo causado por Austin en su entorno filosófico puede atribuirse también, en una parte considerable, a implicaciones fundamentalmente retóricas que algunos estudiosos se aventuran a valorar como inconscientes ${ }^{99}$. En los apartados anteriores han aparecido tropos como el humor, la ironía, la sinécdoque. También son esenciales en Austin la prosopopeya y la metáfora, sobre la que se profundizará en esta última parte.

En el Gorgias Platón estableció que la retórica es adecuada para el discurso persuasivo, pero inapropiada para la filosofía, ya que esta es un discurso superior orientado hacia la verdad ${ }^{100}$. Esta distinción tuvo tanta influencia que hasta Aristóteles la aceptó, por lo que sanciona los usos retóricos en un discurso persuasivo, pero no en un tratado de geometría, por ejemplo. Tal oposición se convierte en una tradición con connotaciones negativas ${ }^{101}$, en un prejuicio que se

96 Hurtado Albir, A., Traducción y traductología, Madrid, Cátedra, 2001, p. 581.

97 Brumme, J. y Resinger, H. (eds.), La oralidad fingida: obras literarias. Descripción y traducción, Madrid, Iberoamericana, 2008.

98 Rajagopalan, K., o. c. p. 295. S. Zwagerman (o. c. p. 149) menciona este extremo cuando habla de las diversas ocasiones que Austin tuvo de repetir las conferencias de $H T W$ en los cinco años anteriores a su presentación en Harvard. J. H. Miller (o. c. p. 12) incluso amplía este plazo y señala que Austin demoró la publicación de casi todo aquello en lo que trabajó en vida, pues seguramente no lo consideraba suficientemente definitivo, según el principio rector de su metodología.

99 Por ejemplo, J. H. Miller (o. c. p. 39) afirma que Austin está haciendo constantemente un uso poético del lenguaje, y que emplea brillantemente la retórica, pero, en su opinión, no reflexiona sobre las implicaciones de ese empleo, sobre si es necesario para expresar lo que quiere.

100 Dasenbrock, R. W., «J. L. Austin and the Articulation of a New Rhetoric» en: College Composition and communication, 38-3, 1987, pp. 291-305 (p. 297).

$101 \quad$ Ibid. p. 298. 
hace extensible a todo discurso científico o académico. Esta idea se ha formulado de una manera más concreta en el ámbito de la filosofía: cualquier rastro estético, retórico o literario en un texto filosófico se ha considerado tradicionalmente como algo accidental u ornamental, una irrelevancia, una distorsión ${ }^{102}$.

Lanzadas a la búsqueda de un mayor respeto y prestigio científicos, las disciplinas humanísticas han trasplantado a lo largo de la historia los modelos y modos de representación considerados como genuinamente científicos: los de las ciencias naturales y físicas. Estos modelos son neutralistas: huyen de la subjetividad; muestran un punto de vista universalista e impersonal; son descriptivos (pretenden reflejar la realidad de los hechos, la verdad); y están desprovistos de marcas estilísticas y afectivas ${ }^{103}$. Pero la aplicación de estos modelos en las disciplinas humanísticas ha acarreado ciertas incongruencias, ya que, según Lang, estos medios de representación no tienen una conexión total con el significado y el alcance de estas ciencias ${ }^{104}$. De hecho, como el propio Lang indica, la presencia de medios de representación retóricos en una obra filosófica puede constituir la mitad de su mensaje, si no su mensaje completo. Hasta Wittgenstein se expresó muy claramente a este respecto en sus Investigaciones filosóficas, renunciando a la propiedad de sus ideas si no llevaban un sello formal que las marcara como suyas, dada la extraordinaria similitud de contenidos entre sus publicaciones y las de otros filósofos ${ }^{105}$ (el propio Austin, sin ir más lejos).

En la obra de Austin se muestra una conciencia plena de esto. En su opinión, el compromiso del discurso filosófico con la verdad era obsesivo y lo llegó a calificar como "falacia descriptiva». La filosofía del lenguaje ordinario supera esta instancia y va más allá de la visión anti-retórica del lenguaje sostenida por filósofos como Platón o Locke. La idea misma de que al hablar nuestra preocupación esencial no es el valor de verdad de nuestras proposiciones, sino los actos que ejecutamos «by saying something», supone adoptar una postura profundamente retórica ${ }^{106}$. Como hemos visto en los apartados anteriores, desde el punto de vista de Austin no se puede trazar una frontera perfectamente nítida entre un discurso orientado hacia afirmaciones verdaderas y un discurso orientado a persuadir. Todo discurso es simultáneamente constatativo y performativo, o dicho de otro modo, se enfoca a la vez hacia su contenido y hacia sus destinatarios ${ }^{107}$. De este modo, Austin recupera para la investigación filosófica dos líneas de la retórica que llevaban mucho tiempo en el descrédito: la persuasión y los tropos. En este último terreno, el modelo de Austin no rechaza el anti-retoricismo del lenguaje científico, y tampoco proclama un uso indiscriminado de tropos y figuras: simplemente trata de mostrar que las afirmaciones directas, literales, no lo son todo en filosofía ${ }^{108}$.

102 Lang, B., The Anatomy of Philosophical Style: Literary Philosophy and the Philosophy of the Literature, Oxford, Basil Blackwell, 1990, p. 2.

103 LANG, B., o. c. pp. 15-16.

104 Ibid. p. 2

105 En LeIBER, J., o. c. p. 58.

106 DasenBrock, R. W., o. c. p. 297.

107 Ibid. p. 298.

$108 \quad$ Ibid. p. 303. 


\subsection{La metáfora en Austin}

Para analizar las metáforas en Austin es preciso proveerse de un marco teórico sumamente cuidadoso y crítico con la teoría de la metáfora en general, y más concretamente con el tratamiento de la metáfora en la ciencia y en la filosofía. A pesar de la tradicional condena de cualquier rasgo retórico en estos campos, lo cierto es que las metáforas proliferan tanto en el ámbito filosófico como en el científico, superando la insistencia en el compromiso con la verdad y saltándose el mito del objetivismo. Por eso la filosofía de la ciencia se ha planteado, entre otras cuestiones, si las metáforas son verdaderas, si pueden referir, si poseen valor cognitivo o si son constitutivas de las teorías ${ }^{109}$. La respuesta a estas preguntas es desigual. Algunos estudiosos opinan que las metáforas son una herramienta meramente explicativa, y otros piensan que sí pueden referir (Boyd), que son cognitivas y que poseen valor de verdad (Black, Hesse $\left.{ }^{110}\right)$.

Los enunciados científicos se rigen por el valor de verdad o falsedad, pero las imágenes (y por ende las metáforas) no pueden ser ni verdaderas ni falsas ${ }^{111}$. Por ello, cuando se establece un modelo, una imagen o una metáfora científica como instrumento de representación de la realidad, esta representación no se basa en criterios de verdad, sino en el criterio clásico de la similitud. La clave es cómo se establece esa relación de semejanza, ya que las cosas tienen muchas formas distintas de parecerse ${ }^{112}$. Está claro que los rasgos semejantes entre una metáfora y lo que representa se seleccionan de una manera convencionalizada, no por una identidad real, así que son comprensibles el recelo y las críticas ante, por ejemplo, la teoría cognitiva de la metáfora (Johnson, Lakoff y seguidores), sobre todo cuando trata de una forma demasiado ramplona las correspondencias entre los dominios fuente y meta, o la mejor comprensión de lo abstracto a través de lo concreto ${ }^{113}$.

Efectivamente, como advierte Rivadulla criticando a Brown, hay que poner un límite razonable a las afirmaciones de que todo en ciencia es metáfora, especialmente si se habla de ciencias cuantitativas ${ }^{114}$. Pero también hay que prevenirse ante la visión de desdén o desprecio hacia las metáforas y hacia las imágenes en general en la ciencia, una postura con profundas raíces históricas, como se ha comprobado. Gómez explica cómo en el siglo XX el positivismo lógico determinó una manera de entender el verdadero conocimiento científico eminentemente axiomática, lingüística y lógica, con lo que todo lo que sea representación imaginística queda excluido $^{115}$. Sin embargo, las metáforas y las imágenes, tal y como afirma la ciencia cognitiva, sí pueden estar en el núcleo del razonamiento científico. Gómez pone

109 Rivadulla, A., "Metáforas y modelos en ciencia y filosofía» en: Revista de Filosofía, 31-2, 2006, pp. 189-202 (p. 192).

$110 \quad$ Ibid. p. 193.

111 Gómez López, S., «Modelos y representaciones visuales en la ciencia» en: Escritura e imagen, 1, 2005, pp. 83-116 (p. 96).

112 «... siempre se puede encontrar un punto de vista desde el cual la imagen puede considerarse semejante a algo», Eco, U., La búsqueda de la lengua perfecta, Barcelona, Crítica, 1994, p. 146.

113 Rivadulla, A., o. c. p. 199.

$114 \quad$ Ibid. p. 200.

115 Gómez López, S., o. c. p. 87. 
como condición para ello la aceptación de la existencia de modelos mentales que activan procesos de simulación de fenómenos cuya materialización visual se realiza a través de imágenes. Y ofrece un argumento muy contundente para la aceptación de las mismas (y de las metáforas, por extensión) como constituyentes de las teorías o incluso como modelos científicos: hay que pensar que gran parte de la actividad científica «se elabora basándose en estos modelos visuales que sustituyen al mundo y no en la experiencia directa de los objetos y fenómenos ${ }^{116}$ ».

Si se enlaza lo que acabamos de decir con todo lo que se ha mencionado en apartados anteriores sobre el carácter imaginístico de los ejemplos en Austin, o sobre la vertiente tropológica de su discurso, no es difícil concluir que los modos de representación pueden ser constitutivos de las teorías, no meros adornos. Y si nos centramos ahora en el análisis de las metáforas en Austin, observaremos cómo esa idea se hace aún más consistente. Por su adecuación al tema, utilizaremos como marco teórico general el desarrollo específico para la filosofía ${ }^{117}$ que generó la teoría de la metáfora conceptual, aunque con un enfoque crítico, según hemos señalado. Ante todo es conveniente distinguir qué tipo de metáforas será objeto de nuestra atención. En distintos lugares la teoría cognitiva deja claro que el sistema de la metáfora conceptual convencional es principalmente inconsciente, automático. Se usa sin esfuerzo evidente, como el sistema lingüístico o el resto del sistema conceptual $^{118}$. Pero el hecho de que estas metáforas estén sistematizadas, fijadas convencionalmente en el lenguaje, no las hace menos vivas. Ese sistema convencional está vivo en el mismo sentido que el sistema gramatical o el fonológico ${ }^{119}$.

Resulta decisivo incidir en esto, porque siempre se podría argüir, sobre todo desde un punto de vista objetivista, que el análisis de las metáforas convencionalizadas carece de interés o de valor científico, al proceder estas de un sistema prácticamente automático, semi-consciente. Sin embargo, cuando alguien está estructurando lo que dice a través de este tipo de metáforas, es muy pertinente reflexionar sobre por qué se han seleccionado unas y no otras, sea cual sea el nivel de consciencia, ya que ese hecho puede dar una idea muy clara del enfoque, conceptualizaciones, intenciones y metodología del autor, sobre todo en el plano científico o filosófico ${ }^{120}$. Cuando se analiza un discurso no solo es preciso explicar lo que su emisor quiso hacer de manera

$116 \quad$ Ibid. pp. 115-116.

117 Lakoff, G. y Johnson, M., Philosophy in the Flesh. The Embodied Mind and its Challenge to Western Thought, N. York, Basic Books, 1999; Johnson, M., «Philosophy's Debt to Metaphor», en: Gibbs, R. W. (ed.), The Cambridge Handbook of Metaphor and Thought, Cambridge, Cambridge University Press, 2008, pp. 39-52. Asimismo, haremos referencia a la obra fundacional de esta corriente (Lakoff, G. y Johnson, M., Metáforas de la vida cotidiana, Madrid, Cátedra, 2012 [1980], traducción de C. González Marín) y a otras fuentes complementarias. No hay que dejar de señalar que la filosofía analítica del lenguaje se ha negado a reconocer la existencia de la metáfora conceptual.

118 LaKoff, G., «The contemporary theory of metaphor», en: Ortony, A. (ed.), Metaphor and Thought, Cambridge, Cambridge University Press, 1993, pp. 202-251 (p. 246).

119 Lakoff, G. y Johnson, M., o. c. 1980, p. 95.

120 A este respecto, M. Johnson (o. c. 2008, p. 42) afirma: «Metaphorically based expressions like these are not just colloquialisms, used loosely in ordinary talk. Once again, the submappings of the metaphor specify the precise details of the semantics of causation and determine what types of inferences we will make». 
efectiva e intencional en una situación determinada, sino que también es esencial intentar reconstruir lo que el sujeto discursivo ha puesto en funcionamiento de una forma no tan controlada o consciente al combinar diferentes clases de recursos ${ }^{121}$.

En el caso de Austin estas consideraciones tienen un valor muy preciso. En su obra se dan, por supuesto, tanto metáforas convencionales como creativas, pero es muy peculiar su forma de utilizar las primeras, porque supone asimismo una total congruencia con una de sus principales tesis teóricas: la de profundizar en las distinciones y sutilezas del lenguaje cotidiano y aprovecharlas para la reflexión filosófica. Por ejemplo, cuando emplea expresiones que contienen metáforas convencionalizadas (to give somebody the round around, to flounder around), Austin consigue mantener los dos planos de esos idiomatismos: el literal, que incorpora metáforas espaciales ('dar una vuelta'; 'hundirse, tambalearse, andar a trompicones') y el figurado, que alude con un sentido irónico a 'engañar', 'confundir' o 'poner las cosas difíciles'. Austin muestra una especial habilidad e interés en que tanto el plano literal (el más poderoso imaginativamente) como el figurado de esas metáforas se mantengan visibles y equilibrados, sin que uno anule al otro, y en este sentido se puede decir que está reavivando todavía más el sistema metafórico convencional y que le está dando un uso consciente y creativo.

Los ejemplos recién mencionados revalidan la tesis cognitivista de que los filósofos, al construir sus teorías sobre el ser o el conocimiento, utilizan los mismos recursos y el mismo sistema metafórico conceptual que cualquier ser humano, aunque después los refinen y sean capaces de ver nuevas conexiones y de intuir implicaciones novedosas ${ }^{122}$. La aplicación al terreno de la filosofía de la teoría de la metáfora conceptual se presenta con la discutible afirmación "without metaphor, there would be no philosophy», pero añade otras consideraciones muy interesantes y mucho más aceptables sobre cómo las metáforas han moldeado históricamente ideas filosóficas esenciales. Desde este punto de vista se analiza la estructuración metafórica de conceptos filosóficos básicos: la causación, la mente, el yo y la moralidad. Y concretamente en Philosophy in the flesh se complementa este esfuerzo con un recorrido histórico de corrientes filosóficas y autores con sus esquemas metafóricos conceptuales más representativos ${ }^{123}$. Toda esta estructuración está constantemente pespunteada por dos categorías fundamentales establecidas en los inicios de esta teoría: la metáfora espacial u orientacional y la metáfora ontológica.

El primer tipo, la metáfora espacial, es el que adquiere mayor preponderancia dentro de la causación, el concepto mejor desarrollado de entre los que se han citado. Se parte del presupuesto de que nuestro sistema visual proporciona una estructura para nuestra habilidad de conceptualizar relaciones espaciales, y de que, en el cuerpo, el lugar del razonamiento es el mismo que ocupa la percepción y el control motor ${ }^{124}$. Por ello en la causación uno de los grandes esquemas complejos

121 Martín Menéndez, S., «Historiografía lingüística y análisis del discurso: las relaciones necesarias» en: Revista argentina de historiografía lingüística, I-1, 2009, pp. 50-66 (pp. 53-54).

122 Lakoff, G. y Johnson, M., o. c. 1999, p. 337; Johnson, M, o. c., 2008, p. 38.

123 Curiosamente, en este repaso, al detenerse en los autores de la filosofía analítica y de la filosofía del lenguaje ordinario, no hay ninguna mención a Austin. Lo mismo sucede en M. Johnson (o. c. 2008).

124 Lakoff, G. y Johnson, M., o. c. 1999, p. 17. 
que se detallan profusamente es el de la metáfora con estructura de evento locativo. Entre las correspondencias y subcorrespondencias (submappings) de este esquema general hay algunas que son esenciales en Austin y en HTW, como «Difficulties are Impediments to Motion» $\mathrm{y}$ "Longterm, Purposeful Activities are Journeys ${ }^{125}$ ».

«Difficulties are Impediments to Motion» es una submetáfora jerarquizada que se categoriza en cinco tipos: blockages, features of the terrain, burdens, couterforces $\mathrm{y}$ lack of an energy source ${ }^{126}$. Muchos de los ejemplos que hallamos en Lakoff y Johnson son idénticos a los que aparecen en HTW. En cuanto al primer tipo, blockages, encontramos en Austin la misma expresión, run into something:

When it was suggested that we embark on a programme of making a list of explicit performative verbs, we ran into some difficulties over the matter of determining whether some utterance was or was not performative, or anyway, purely performative ${ }^{127}$.

En su acepción primaria ${ }^{128}$, este phrasal verb significa entrar en un área de mal tiempo durante un viaje, y desde ahí se fija un significado más general, 'experimentar dificultades'; y otro más específico y violento: 'chocar con algo'. Todas estas precisiones semánticas pueden equipararse a subcorrespondencias de la metáfora compleja general, como «External events are large objects». En primera instancia, Austin está visualizando programme como una nave, una embarcación sometida a los embates del mal tiempo, de una tormenta, por ejemplo. La primera acepción de to embark es esa, 'to get onto a ship, to put something onto a ship'. To embark on/upon sth se define como 'to start to do something new or difficult'. Este es uno de los momentos de la obra en el que Austin se plantea lo adecuado o no del recorrido realizado y abre un nuevo comienzo ( $I$ It's time to make a fresh start on the problem ${ }^{129}$ ») que se corresponde con la submetáfora «Undoing Progress is Backward Movement», dentro de la clase más general «Long-term Activities are Journeys». Mediante el empleo de este mapa metafórico, Austin consigue darle a lo que está haciendo un carácter de aventura, de descubrimiento, de empresa dificultosa.

Todas esas expresiones de reinicio («fresh start») cuadran a su vez con una subcorrespondencia metafórica que se encuentra en la misma red que las anteriores: "Starting a Purposeful Action is Starting out on a Path». De hecho, se localizan en $H T W$ ejemplos que hacen alusión directa a la metáfora del camino: «Just to spur us on our way ${ }^{130}$ ». La fusión de los esquemas metafóricos del viaje y del camino, plagados ambos de dificultades, tiene unas implicaciones teóricas muy potentes e interesantes en Austin. Para empezar, el esquema del viaje resulta

$125 \quad$ Ibid. p. 173

$126 \quad$ Ibid. pp. 177-178.

127 HTW, p. 109.

128 Los diccionarios de referencia en todo el artículo y específicamente en esta sección han sido el Cambridge Advanced Learner's Dictionary (disponible en http://dictionary. cambridge.org) y el Oxford English Dictionary (disponible en http://oed.com).

129 HTW, conferencia VIII, p. 91. Por esta razón S. Felman (o. c. p. 63) habla de la importancia de la anáfora en Austin: «Like Don Juan's life, austinian research is thus modeled on anaphora, on repetition of beginnings».

$130 H T W$, p. 90. 
sumamente flexible para el pensamiento filosófico. Hay viajes muy bien planeados, con destinos muy concretos, pero otros «may or may not prescribed or ultimate destinations. Some journeys are just wanderings. Some are semistructured with some intermediate, perhaps vague, destinations ${ }^{131} »$. Esto encaja perfectamente con el principio teórico-metodológico austiniano de no imponer precozmente unas conclusiones definitivas en el debate filosófico.

Por otra parte, el esquema metafórico del camino muestra una extraordinaria adecuación con respecto al concepto de causación. Más concretamente, lo que Lakoff y Johnson denominan «The Causal Path» representa exactamente otra de las tesis teórico-metodológicas de Austin: «... people tend to wind up at places that the paths and roads they are already on lead to. Thus, if you are travelling, the path or road you are already on is a crucial determining factor in where you will wind up $^{132}$ ». Por tanto, no es casual que las metáforas convencionales de HTW seleccionen la imagen de un recorrido filosófico inusual, lleno de obstáculos, no el camino habitual por donde todo el mundo transita y que conduce a los mismos sitios. En este último sentido, el segundo tipo de dificultades, features of the terrain, cumple un papel revelador y es especialmente abundante en Austin:

- So far then we have merely felt the firm ground of prejudice slide away beneath our feet. But now how, as philosophers, are we to proceed? One thing we might go on to do, of course, is to take it all back; another would be to bog, by logical stages, down. But all this must take time. Let us first at least concentrate attention on the little matter already mentioned in passing — this matter of 'the appropriate circumstances ${ }^{133}$.

- I must explain again that we are floundering here. To feel the firm ground of prejudice slipping away is exhilarating, but brings its revenges ${ }^{134}$.

- We have then to take a further step into the desert of comparative precision. We must ask: is there some precise way in which we can definitely distinguish the performative from the constative utterance ${ }^{135}$ ?

En estos ejemplos la horizontalidad del «firme suelo» del prejuicio se rompe, nos deslizamos (slide away) y nos hundimos o avanzamos con dificultad mediante un phrasal verb: to bog something/somebody down (in something), que literalmente es 'hundirse en el lodo'. En el segundo fragmento el orden de la red metafórica está alterado, como en un quiasmo: aparece primero el hundimiento, el «andar a trompicones», esta vez a través de floundering (ya había aparecido antes to flounder around, con el mismo sentido); y después «the firm ground of prejudice», que se desliza, circunstancia que Austin considera incluso divertida. La sugestiva imagen de arenas movedizas representada por to bog down se reformula en el siguiente fragmento a través de la metáfora de desert, unidad léxica que incluye en sí misma la idea de dificultad para avanzar, de hundimiento.

\footnotetext{
131 Lakoff, G. y Jonhson, M., o. c. 1999, p. 180.

132 Ibid., p. 189; Johnson, M., o. c. 2008, p. 42-43.

$133 \quad H T W$, p. 13. Una vez más, la expresión metafórica que aparece en $H T W$ coincide con la que Lakoff y Johnson emplean para ejemplificar este aspecto: «If you are physically stuck in a bog», «if you are bogged down on a project» (LAKOFF, G. y Johnson, M., o. c. 1999, p. 178).

${ }^{134} H T W$, p. 61.

$135 H T W$, p. 55.
} 
Estas son solo algunas de las metáforas convencionales de HTW que representan un contraste entre horizontalidad y verticalidad en la que los pensadores o los propios conceptos, a medida que se desplazan, sufren un proceso de hundimiento que no se valora como negativo, al contrario de lo que predica la teoría de la metáfora conceptual (LO MALO ES ABAJO), sino que incluso es exhilarating. La intención con la que están empleadas parece hallarse en franca contradicción con el sentido de las submetáforas que les corresponden: «Lack of Purpose is Lack of Direction» (por ejemplo en los casos en los que aparece to flounder around); o «Self control is being in one's normal location", "Self control is being on the ground", que son metáforas del $\mathrm{Yo}^{136}$ en las que lo espacial y lo ontológico comienzan a hibridarse, como sucede frecuentemente en $H T W$. Estas últimas plantean una relación clave con las que pueden denominarse metáforas de la caída en Austin, que ya se vislumbran en los ejemplos anteriores a través de unidades léxicas como to slide away y que resultan explícitas en fragmentos como el siguiente, en el que previamente se habían estado haciendo distinciones sobre los tipos de misfires:

So then we may seem to have armed ourselves with two shiny new concepts with which to crack de crib of Reality, or as it may be, of Confusion - two new keys in our hands, and of course, simultaneously two new skids under our feet. In philosophy, forearmed should be forewarned ${ }^{137}$.

Aparecen aquí metáforas ontológicas que equiparan los conceptos con objetos (keys, skids), en una línea aristótelica ${ }^{138}$. El que reflexiona aparece «armado», no con un casco o una espada, sino con conceptos que se convierten en "llaves brillantes» en sus manos y en "patines» deslizantes en sus pies. Esta manera de armarse parece bastante ridícula y poco provechosa, por eso en el idiomatismo que viene a continuación Austin cambia deliberada e irónicamente el orden de palabras: «In philosophy forearmed should be forewarned». Parece dar a entender que pertrecharse de todos esos conceptos no garantiza el éxito en la reflexión filosófica, ya que los skids provocan un movimiento descontrolado. Es decir, esos conceptos son tanto llaves que ayudan a la comprensión como patines que pueden llevarnos más deprisa y también hacernos caer, fracasar en el razonamiento.

Está claro que las imágenes del hundimiento y la caída en Austin van siempre paralelas a la ironía y a la comicidad. Están subvirtiendo el propio esquema canónico de la metáfora conceptual, del mismo modo en que se invirtieron el papel de la filosofía y de los manuales de autoayuda en el título de la obra. Se está

136 LaKoff, G. y Johnson, M., o. c. 1999, p. 220.

$137 H T W$, p. 25.

138 «Las ideas son objetos físicos» (LAKofF, G. y Johnson, M., o. c., 1999, pp. 373-374) es una submetáfora muy presente en Aristóteles. Por falta de espacio no podemos desarrollar más extensamente las metáforas conceptuales ontológicas en Austin, pero no podemos dejar de mencionar la antítesis metafórica entre rough y refine, que está profundamente imbricada en la estructura de $H T W$. Cuando se hace referencia a reflexiones o distinciones realizadas en las conferencias I a VI, aparecen frecuentemente calificadas con el adjetivo rough y sus derivados (roughly). A partir del «fresh start» de la conferencia VIII, la metáfora ontológica que representa rough se sustituye por otra antitética: refine, refinements. Este medio le permite a Austin, de una manera muy coherente, presentar su reflexión filosófica como un objeto en constante cambio, que se va puliendo y perfeccionando en colaboración con sus receptores. 
dando carta de naturaleza a lo anormal, incluyendo lo que estaba fuera mediante los modos de representación. El hecho de caer o lo que está abajo dejan de ser «lo malo». Casi todos los pasajes en los que está presente el humor en HTW (que son muchos), sobre todo los relacionados con la posibilidad de hundimientos o caídas, son momentos esenciales en los que se plantean dudas, en los que se cuestiona el conocimiento $^{139}$, tanto si se trata de metáforas como de esos ejemplos que son, prácticamente en su totalidad, fallos, cosas que salen mal.

La mejor ilustración de lo que acabamos de decir es la metáfora representada por to bog down, que sobrevuela toda la obra y que Miller interpreta como la tenaz resistencia de Austin a rematar sus trabajos de una manera conclusiva ${ }^{140}$. El propio Austin hace esta confesión cuando la misma imagen aparece en «Other Minds», añadiendo el factor centro/periferia, que es uno de los esquemas visuales universales en la conceptualización de las relaciones de espacio ${ }^{141}$. Austin afirma que en el desarrollo de sus ideas solo ha alcanzado la periferia de la cuestión y, además, hundiéndose, que ni siquiera se ha acercado a la parte central. Miller ofrece una sugerente explicación para este hecho: parece como si Austin se resistiese a llegar a una conclusión no deseada a la que su pensamiento, sin embargo, tiende inexorablemente. Sería un tipo de conclusión como el que hemos anticipado páginas más arriba: el lenguaje es performativo en sí mismo, estructuralmente, más allá de las intenciones del que habla. Ese centro al que no se quiere llegar ejerce una fuerza centrípeta con la que hay estar en constante lucha ${ }^{142}$.

Las interpretaciones más recientes sobre la ubicación de Austin en la filosofía occidental coinciden con el análisis de Miller. Glendinning sostiene que Austin intenta mantener un «intrigante» equilibrio ${ }^{143}$. Por una parte, quiere liberarse de unos marcos de pensamiento prefijados, pero, por otra, no puede aislarse totalmente del pensamiento filosófico tradicional. Así que crea una estrategia, entre inmersión y aislamiento, que consiste en situarse en los márgenes de la filosofía tradicional. En lugar de ocuparse de la lógica de las proposiciones, investiga los performativos; en vez de estudiar la posibilidad del conocimiento, explora la percepción; en lugar de estudiar la lógica de las razones, se interesa por las excusas, etc. Glendinning opina que esta estrategia ha sido mal expuesta y mal entendida (una vez más) tanto por los críticos de Austin como por sus partidarios. Seguramente esto se debe

139 Felman, S., o. c. p. 119; Zwagerman, S., o. c. p. 142.

140 Miller, J. H., o. c. p. 170.

141 LAKoff, G. y Johnson, M., o. c. 1999, p. 23.

142 Miller, J. H., o. c. pp. 171-172. Incluso aquí se da la presencia de la metáfora conceptual. Cuando en Philosophy in the flesh (Lakoff, G. y Johnson, M., o. c. 1999, pp. 236237) se analiza la estructuración metafórica que la filosofía ha dado al concepto de mente, aparecen submetáforas como «Ideas are Locations» $\mathrm{O}$ «Thinking about $\mathrm{X}$ is Moving in the Area Around X», en las que la razón se enfoca como una abrumadora fuerza natural que empuja al pensador de una idea-lugar a otra. Seguir esa línea de pensamiento que lleva a una conclusión natural es lo razonable, pero «to refuse to reach a natural conclusión is to resist the force of reason, to be unreasonable or irrational», que es lo que, en cierto modo, le sucede a Austin: está echando un pulso con su propio proceso de razonamiento como estrategia metodológica de su teoría filosófica.

143 Glendinning, S., «Unmasking the Tradition», en: Gustafsson, M. y Sørli, R., o. c. pp. 32-50. En Gustafsson, M., o. c. 2011, pp. 21-22. 
a la gran aporía global de la que Austin se sirvió para exponer su trabajo, como hemos visto. En cualquier caso, queda claro que en esta filosofía de los márgenes las herramientas retóricas cumplen un papel consciente y crucial.

Universidad de Extremadura

María Isabel Rodríguez Ponce mirponce@unex.es

[Artículo aprobado para publicación en diciembre de 2016] 